TP Periodica Polytechnica

Chemical Engineering

58(2), pp. 171-178, 2014

DOI: 10.3311/PPch.7388

Creative Commons Attribution (i)

RESEARCH ARTICLE

\section{Physico-Chemical Study of Coating Formulation Based on Natural Apatite for the Elaboration of Microfiltration Membrane}

\author{
Hassen Nasri ${ }^{1}$ / Sabeur Khemakhem ${ }^{1} /$ Raja Ben Amar ${ }^{1 *}$
}

RECEIVED 3 MARCh 2014; ACCEPTED AFTER REVISION 16 June 2014

\section{Abstract}

This work deals with the experimental characterization of the rheological properties of a dip solution which will be used to elaborate a new apatite/clay microfiltration membrane by deposition using slip casting process of the active layer on a tubular support based on natural clay previously prepared.

So, the rheological study of various coatings with different concentration of apatite powder, polyvinyl alcohol (PVA) and water under different conditions regarding temperature and stirring time was done. It was found that the suitable suspension should follow a rheo- thickner behavior having a viscosity in the range of 30-35 $\mathrm{mPa}$ s at room temperature of 25 to $30^{\circ} \mathrm{C}$. The optimum conditions then found to achieve these properties were: a suspension of $4 \%$ of apatite, $40 \%$ of PVA stirred for 180minutes.

The study reveals also that the thickness of the active membrane layer depends on the coating time.

\section{Keywords}

Microfiltration layer $\cdot$ Rheological behavior $\cdot$ dip solution • viscosity $\cdot$ apatite/clay

\footnotetext{
${ }^{1}$ Laboratoire des Sciences de Matériaux et Environnement, Université de Sfax, Faculté des Sciences de Sfax, Route de Soukra Km 4, 3038, Sfax, Tunisie

*Corresponding author, e-mail: benamar.raja@yahoo.com
}

\section{Introduction}

Commercial ceramic membranes have undergone a rapid growth during the last two decades. Advantages of ceramic membranes include resistance to corrosive feed, high temperature applicability, consistency in high pressure application and long life $[1,2]$. The major challenges for future development of inorganic membranes are to produce low-cost membranes from natural materials such as clay and apatite which are in abundance, need lower firing temperature than metal oxide materials and have high separation performances suitable for treatment of large volumes of liquid [2-5]. To increase the reliability of the tenacity of these membranes having an asymmetric structure composed of at least two layers which are the support and the active layer, there is still a need for improvement in rheological properties of dip solution required for the preparation of microfiltration membrane layer.

The control of the rheological parameters of the dip solution is of significant importance for optimizing the final composition of the suspension. Indeed, the rheological properties depend on the physico-chemical characteristics of the raw material used and on the conditions under which the dip solution was prepared. Besides, the active layer thickness and microstructure of the membrane are mainly controlled by the viscosity of the dip solution which depends mainly on the particle size, the nature of the raw material, the addition of polymer and on temperature [6-9]. Specific apatite properties such as chemical resistance, hydration, and viscosity make it a valuable material to use as coating powder in membrane preparation for a wide range of applications $[10,11]$. The apatite suspensions display varying rheological properties that are highly dependent on the nature of the apatite, suspension preparation technique, concentration, $\mathrm{pH}$, ionic strength, etc [12-13]. In its natural state, apatite is identified by the general formula $\mathrm{M}_{10}\left(\mathrm{XO}_{4}\right)_{6} \mathrm{Y}_{2}$ where ' $\mathrm{M}$ ' is a cation such as $\mathrm{Ca}, \mathrm{Sr}, \mathrm{Ba}, \mathrm{Pb}$, etc. ' $\mathrm{X}$ ' can be $\mathrm{P}, \mathrm{As}$, $\mathrm{Si}$, etc., while ' $\mathrm{Y}$ ' is a term relative to anions, such as $\mathrm{OH}^{-}, \mathrm{F}^{-}, \mathrm{Cl}^{-}$or other groups [14-15]. Apatite is known in the phosphate mines as the principal constituent of the ore while in the biological environment the principal component of animal bones and 
teeth. Apatite possesses a wide range of physicochemical properties and is used as raw material in many chemical industries such as the preparation of the artificial fertilisers, manufacture of catalysts, osseous prostheses. The system hydroxyapatite additives is usually used in the manufacture of bioceramics and for the potential application for preparing ceramic membranes [3-16]. The properties of the apatite suspensions in water are largely modified by the presence of polymers, electrolytes, etc. Many studies reported in the literature, treated as subject the rheological behavior of systems like "water- apatite- additive" and „water-clay-additive" where the additives were often a polymer. Most of these studies were devoted to the colloidal and/or rheological properties of these suspensions and on the effect of polymeric additives in order to obtain the optimal composition of the suspension [3, 17-20]. These suspensions exhibit a pseudoplastic behavior which is characterized by a decrease in viscosity with an increase in the rate of shearing according to the dispersant concentration [17]. The rheological study for a suspension of hydroxyapatite - alumina platelets- dispersion, including a percentage less than $30 \%$ vol of $\mathrm{Al}_{2} \mathrm{O}_{3}$ exhibited a quasi-Newtonian behavior maintained in all suspensions beyond $30 \%$ vol $\mathrm{Al}_{2} \mathrm{O}_{3}$ [20]. Masmoudi et al. [3] found that a suspension composed of $10 \%$ hydroxyapatite, $40 \%$ (PVA) have a Bingham plastic behavior and is adequate to prepare apatite microfiltration layer on a natural apatite macroporous tubular support.

The objective of the present work is to study the rheological behavior of a dip solution based on Tunisian apatite to determine the optimum composition for the preparation of microfiltration apatite layer to deposit by slip casting technique on a macroporous tubular clay support. The adhesion of the layer to the macroporous ceramic support is achieved by capillary suction. The thickness of the layer depends on the physico-chemical properties of medium, as well as the viscosity of the slip.

\section{Materials and methods}

\subsection{Elaboration of membrane coating layer}

Porous ceramic clay tubes of $150 \mathrm{~mm}$ length with inner diameter of $6 \mathrm{~mm}$ and outer diameter of $10 \mathrm{~mm}$ having average pore size of $63 \mu \mathrm{m}$ described in a previous work [2] were used as supports.

The coating formulation was prepared using apatite powder (particle size of $20 \mu \mathrm{m}$ ) Then a quantity of a $12 \mathrm{wt} \%$ aqueous solution of polyvinyl alcohol (PVA) (Rhodoviol 25/140 - Prolabo) was added as binder.

Desagglomeration of the mineral powder and homogenisation of the coating formulation was ensured by mechanical stirring using an ordinary magnetic stirrer at its maximum speed.

The slip casting process was applied to coat the support tube to elaborate microfiltration membrane as described in Fig. 1. The coating formulation was poured inside the support for a few minutes at room temperature while the tube was closed at one end. A layer is then formed on the inner side of the porous tube due to capillary suction. Afterwards, the excess was drained out.

The green layer is then dried during $24 \mathrm{~h}$ at room temperature and fired at $750^{\circ} \mathrm{C}$. The firing temperature and the temperature schedule followed were chosen basing on a previous work done in our laboratory to prepare a natural apatite microfiltration layer on a natural apatite support.

The firing temperature was fixed at $750^{\circ} \mathrm{C}$ for $3 \mathrm{~h}$. A soaking time for 2 hours at a temperature of $250^{\circ} \mathrm{C}$ is necessary to burn out completely the organic binder [3].

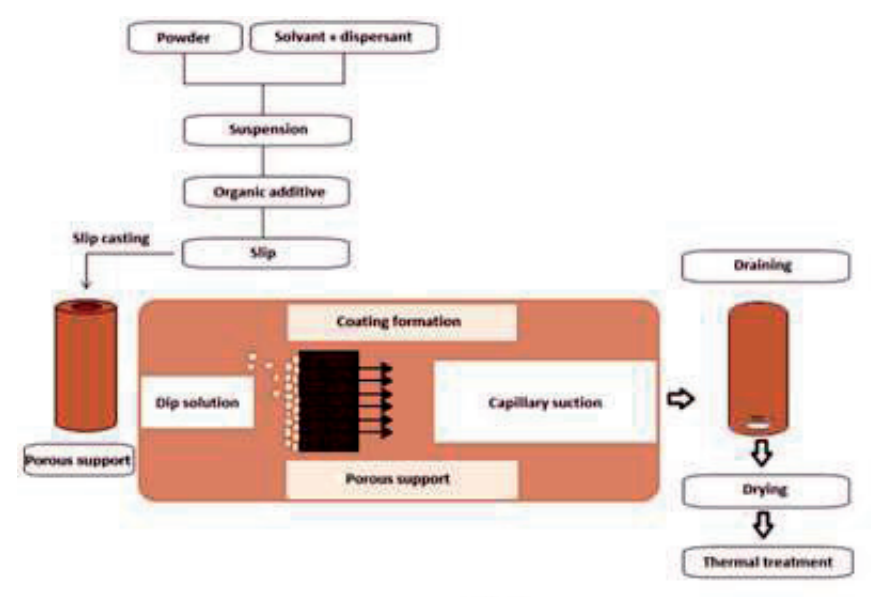

Fig. 1. Scheme of slip casting process

\subsection{Optimization of the suspension composition}

Different coating formulations B.n differing by PVA concentration $(1<\mathrm{n}<12)$ and apatite powder $(13<\mathrm{n}<17)$ were used to determine the optimal composition of the final layer.

At the first time, the apatite powder quantity was kept at $4 \%$ when the PVA aqueous solution percentage was varied and then, at the second time, the PVA aqueous solution percentage was fixed to $40 \%$ when the apatite powder percentage was varied (Tables 1 and 2).

\subsection{Rheological characterization of the suspension}

The viscosity is an important parameter to determine the slip optimal composition. It was measured just before slip casting by using a rotary viscosimeter Tve-05 (LAMY).

Viscosity measurements were taken with two modules: MS-BV 1; MS-BV 10. During measurement of the viscosity at different temperatures, a thermostatic bath was placed under the cup.

\subsection{Membranes characterization}

SEM (Scanning Electron Microscope) images were determined using a Hitashi scanning electron microscope type Philips XL 30 was used in order to visualize the surface quality of the membrane layer and to follow its morphological evolution according to the composition of the coating formulation. 
Tab. 1. Composition of coating formulation prepared with different percentage of PVA using $4 \%$ of apatite suspension.

\begin{tabular}{ccc}
\hline coating formulation & \% of PVA & \\
\hline B. 1 & 10 & $\%$ of water \\
B. 2 & 15 & 86 \\
B. 3 & 20 & 81 \\
B. 4 & 25 & 76 \\
B. 5 & 30 & 71 \\
B. 6 & 35 & 66 \\
B. 7 & 40 & 61 \\
B. 8 & 50 & 56 \\
B. 9 & 60 & 46 \\
B. 10 & 70 & 36 \\
B. 11 & 80 & 26 \\
B. 12 & 90 & 16 \\
\hline
\end{tabular}

a: the percentage of PVA here is relatif to the quantity of the $12-w t \%$ PVA aqueous solution added to the powder-water dispertion.

Tab. 2. Composition of coating formulation prepared with varying percentage of apatite in 40\% PVA aqueous solution.

\begin{tabular}{ccc}
\hline coating formulation & \% of apatite & $\begin{array}{c}\text { \% of water/PVA } \\
\text { aqueous solution }\end{array}$ \\
\hline B. 13 & 2 & 94 \\
B. 14 & 4 & 92 \\
B. 15 & 6 & 90 \\
B. 16 & 8 & 88 \\
B. 17 & 10 & 86 \\
\hline
\end{tabular}

b: mixture of 12 wt \% PVA aqueous solution and water

\subsection{Theory of rheology}

Rheology is the study of the deformation and flow behavior of matter. Rheological properties vary from viscous fluids to elastic solids, defining the spectrum of possible material responses to applied stress $(d F)$ or shear stress ( $\tau$ or D). The generating flow properties are described in constitutive equations that establish a correlation between stress and kinematics [21].

In the most common rheological experiment a shear rate or shear stress is applied to the sample and a flow curve (viscosity $\eta$ as a function of shear rate $D$ ) is recorded.

For dilute polymeric solutions or dilute suspensions and emulsions, Newtonian flow properties was mostly detected [21]. In

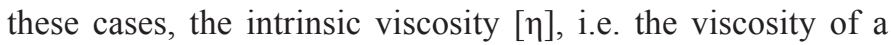
single aggregate suspended in a solvent is the most important parameter for characterization. More concentrated dispersed systems, colloidal and non-colloidal, show various non-Newtonian flow properties such as shear-thinning, shear thickening as well as transient changes of the viscosity.
The viscosity function $\eta(\mathrm{D}, t)$ expressed in Pa.s (IS unit) can be described by different models following :

- Newtonian law: $\tau=\eta \mathrm{D}$

- Power law model: $\tau=\kappa \mathrm{D}^{\mathrm{n}}$

where $\eta(\mathrm{Pa}$.s or PI) is the viscosity, $\tau(\mathrm{Pa})$ the shear stress, $\mathrm{D}$ $\left(\mathrm{s}^{-1}\right)$ the shear rate, $\kappa$ the flow coefficient, and $n$ the flow index which may vary from $n=1$ (leading to the Newtonian law) to $n<1$ or $n>1$ to describe shear-thinning or shear-thickening flow behavior respectively.

In this work, rheological measurements were carried out in both steady-state and dynamic regimes. The viscosity and the rheological behaviour of the suspensions were measured at different weight concentration of natural apatite powder in PVA aqueous solution - water mixture using a cone-plate viscometer with a varying shear rate in the range of $50-600 \mathrm{~s}^{-1}$ at different temperatures. With this kind of suspensions, the samples undergo a simple shear deformation. The evolution of stress $(\tau)$ as a function of shear rate (D) characterises the rheological steady state behaviour of the suspension. In steady-state regime, stress and strain rate are related by the following tow relationships depending on the rheological behaviour:

Power law model: $\boldsymbol{\tau}=\mathbf{K} \mathbf{D}^{\mathbf{n}}$

Bingham model: $\boldsymbol{\tau}=\boldsymbol{\tau}_{\mathbf{0}}+\boldsymbol{\eta}_{\mathrm{p}} \mathrm{D}$

Where $\boldsymbol{\eta}_{\mathrm{p}}$ (Pa.s or PI) is Bingham viscosity, $\boldsymbol{\tau}$ and $\boldsymbol{\tau}_{\mathbf{0}}(\mathrm{Pa})$ are shear stress and yield stress, respectively, $\mathrm{D}\left(\mathrm{s}^{-1}\right)$ the shear rate.

\section{Results and discussion}

\subsection{Influence of temperature}

The influence of the temperature on the suspension viscosity was studied using different concentrations of PVA (15-35\%) and apatite $(2 \%-10 \%)$.

The mineral study used for coating was tested at varying temperatures ranging from 25 to $50^{\circ} \mathrm{C}$. As expected, a rise of temperature leads to a decrease of the suspension viscosity (Figs. 2a and 3a.) according to an exponential relationship (Law of Arrhenius) whose expression is given by [22]:

$$
\eta=A \exp \left(\frac{E a}{R T}\right)
$$

Where $\mathrm{A}$ is the pre-exponential factor, $\mathrm{E}_{\mathrm{a}}$ is the activation energy for viscous flow, $\mathrm{R}$ is the gas constant $\left(8.314 \mathrm{~J} \mathrm{~mol}^{-1} \mathrm{~K}^{-1}\right)$, and $\mathrm{T}$ is the absolute temperature. The logarithm of the viscosity plotted against the inverse of temperature bits well aspect Arrhenius relation.

Figs. 2a and 3a show that the viscosity increases considerably with increasing the concentration of apatite powder and PVA (the effect is more intense for the PVA \% parameter) but decreases with the increase of the temperature in the range $25-50^{\circ} \mathrm{C}$. The influence of temperature on the composition and viscosity can be described using Arrhenius Law. The determination of the activation energy Ea shows a pronounced sensitivity of the viscosity to temperature changes [24]. Figs.2b and $3 b$ 

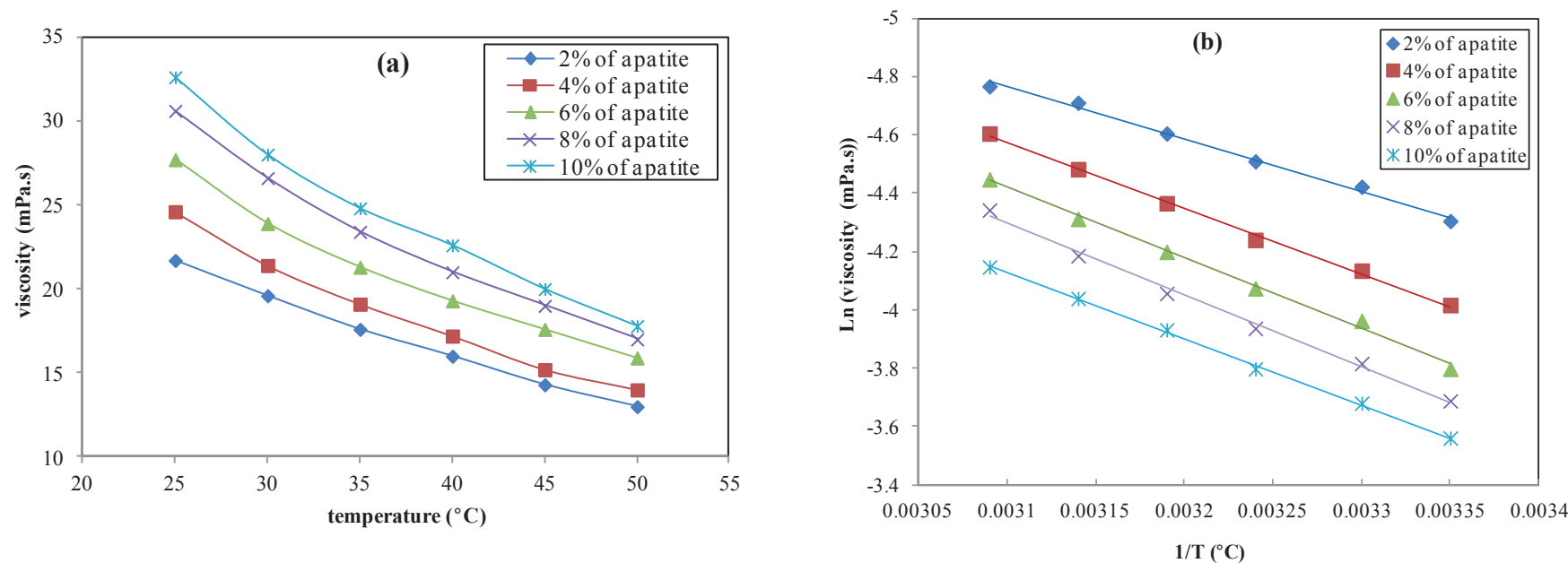

Fig. 2. Evolution of viscosity with the temperature for different apatite concentrations
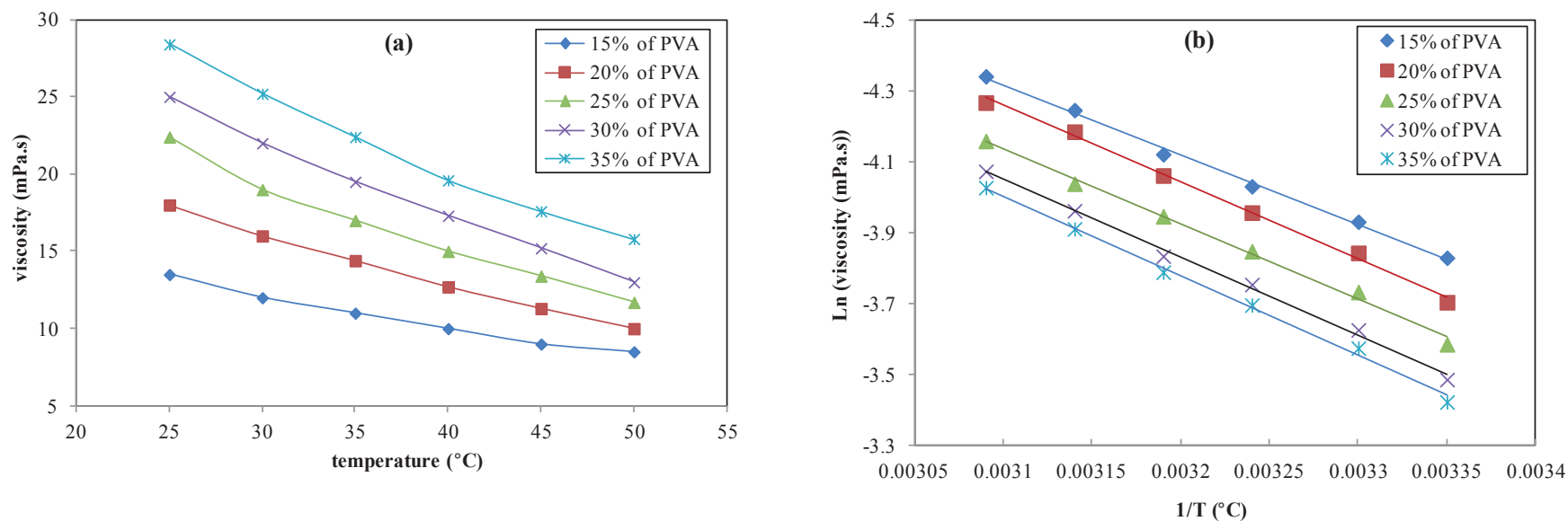

Fig. 3. Evolution of viscosity with the temperature for different PVA concentrations

show an evolution accorded to Arrhenius law for the different prepared suspensions with an increase of the logarithmic viscosity with the percentage of loading of PVA and apatite in the temperature range between $25^{\circ} \mathrm{C}$ and $50{ }^{\circ} \mathrm{C}$. A straight line was obtained using Arrhenius model which fitted reasonably well with the experimental data and gave high $\mathrm{R}^{2}$ equal to 0.99 with 99\% confidence level.

Table 3 lists the corresponding flow activation energy $\Delta \mathrm{Ea}$ and the related fit stability index $\mathrm{R}^{2}$ for different suspensions. With increasing concentration of apatite powder and PVA, a pronounced increase of the flow activation energy can be observed. Such results are in agreement with the values given in the literature $[24,25]$ and are due to the increasing interaction of the particles with the polymer.

In slip casting process, capillary suction is the driving force that causes the layer deposition on the inner side of the support. Then, to obtain a good and homogenous layer, the suspension does not have to be very viscous nor fluid. The effect of PVA and mineral powder percentages on the viscosity of the suspension is due to the fact that increasing concentration would have a direct effect on the fluid internal shear stress while the temperature effect is obviously due to a weakening

Tab. 3. Estimation of the flow activation energy Ea for apatite-PVA

\begin{tabular}{|c|c|c|c|c|c|c|c|c|c|c|}
\hline suspensions & $\begin{array}{l}2 \% \text { of } \\
\text { patite }^{a}\end{array}$ & $\begin{array}{c}4 \% \text { of } \\
\text { apatite }^{a}\end{array}$ & $\begin{array}{c}6 \% \text { of } \\
\text { apatite }^{a}\end{array}$ & $\begin{array}{c}8 \% \text { of } \\
\text { apatite }^{a}\end{array}$ & $\begin{array}{l}10 \% \text { of } \\
\text { apatite }^{a}\end{array}$ & $\begin{array}{c}15 \% \text { of } \\
\text { PVA }^{b}\end{array}$ & $\begin{array}{c}20 \% \text { of } \\
\text { PVA }^{b}\end{array}$ & $\begin{array}{c}25 \% \text { of } \\
\text { PVA }^{\mathrm{b}}\end{array}$ & $\begin{array}{c}30 \% \text { of } \\
\text { PVA }^{b}\end{array}$ & $\begin{array}{c}35 \% \text { of } \\
\text { PVA }^{b}\end{array}$ \\
\hline$\Delta \mathrm{Ea}(\mathrm{KJ} / \mathrm{mol})$ & 14.36 & 16.55 & 19.87 & 20.33 & 20.70 & 15.49 & 16.85 & 20.86 & 21.75 & 22.28 \\
\hline $\mathrm{R}^{2}$ & 0.993 & 0.997 & 0.995 & 0.995 & 0.998 & 0.996 & 0.996 & 0.094 & 0.096 & 0.096 \\
\hline
\end{tabular}

a: PVA aqueous solution was fixed at $40 \%$

b: Apatite powder $\%$ was fixed at $4 \%$ 


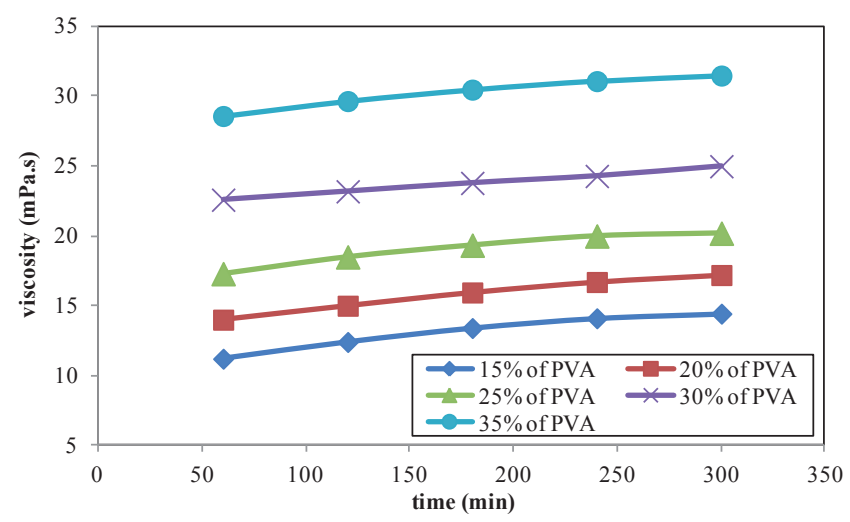

Fig. 4. Evolution of the viscosity with the time of stirring for different PVA concentration (apatite percentage is $4 \%$ )

of inter-particle and inter-molecular adhesion forces [23]. The temperature should be well controlled and maintained under $30^{\circ} \mathrm{C}$ to keep the viscosity in the rage of $25 \mathrm{~m}$.Pas which is a value mentioned in other studies where microfiltrations membranes were made from the same material or other low cost and natural materials $[3,26]$. By the other hand, the PVA and the mineral powder percentage, have a direct influence on the suspension viscosity. This influence is more important for low temperatures. A temperature of $25^{\circ} \mathrm{C}$ to $35^{\circ} \mathrm{C}$ will be retained since the layer deposition process is technically possible only at low temperatures. The PVA percentage have the stronger effect on the viscosity, so, it is of interest to study its effect on the rheological behavior of the suspension to choose a two or three compositions for layer deposition.

\subsection{Influence of PVA percentage}

Figs. 4 shows that the viscosity of the suspension increases slightly depending on the stirring period. However, the increase of PVA percentage leads to a considerable increase of the viscosity (Fig 4). Such rheological behavior is explained by the different types of interactions susceptible to be established between PVA used as Binder and apatite particles which depend on the concentration of both of them [27]. In conclusion, a stirring time of 180 minutes is a medium duration that can be used when preparing the suspension to be used.

From Fig. 5, it can be noticed that dynamic viscosity for almost all the prepared suspensions (B.1, B.3, B.5, B.7, B.8, B.9, B.10 and B.11) increases with the speed of shearing D except B.12. According to the equation which describes the law of suspension behavior, these samples show a rheo-thickener behavior generated by an increase in inter-particle interactions due to increasing the concentration of PVA and formation of complex flocculated structures [28]. We also observe that viscosity of the suspensions is related to apatite powder concentration. Dynamic viscosity decreases slightly according to the speed of shearing, but this variation remains insufficient for the determination of the nature of the behavior of such suspension. For identifying the rheological behavior, the variation of

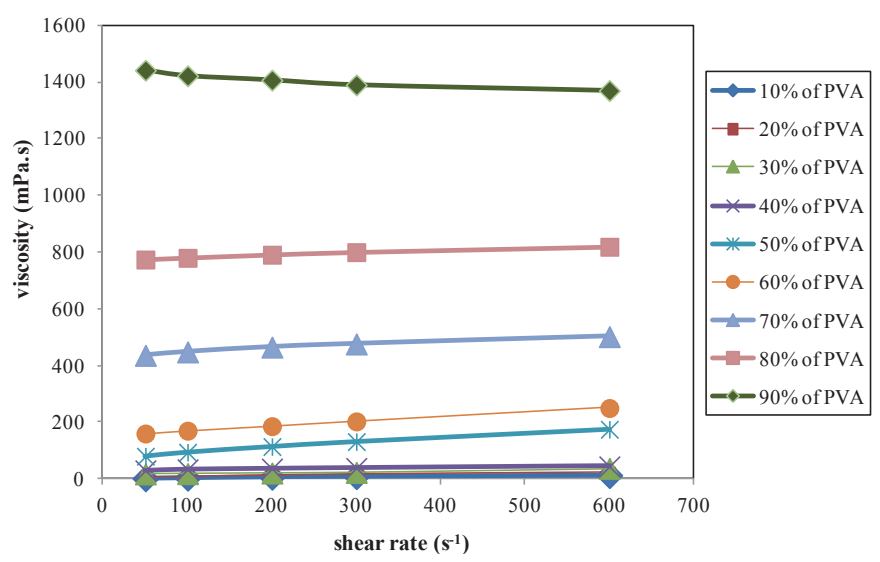

Fig. 5. Evolution of the viscosity with the percentage of PVA $\left(\mathrm{T}=25^{\circ} \mathrm{C}\right.$ and $4 \%$ of apatite)

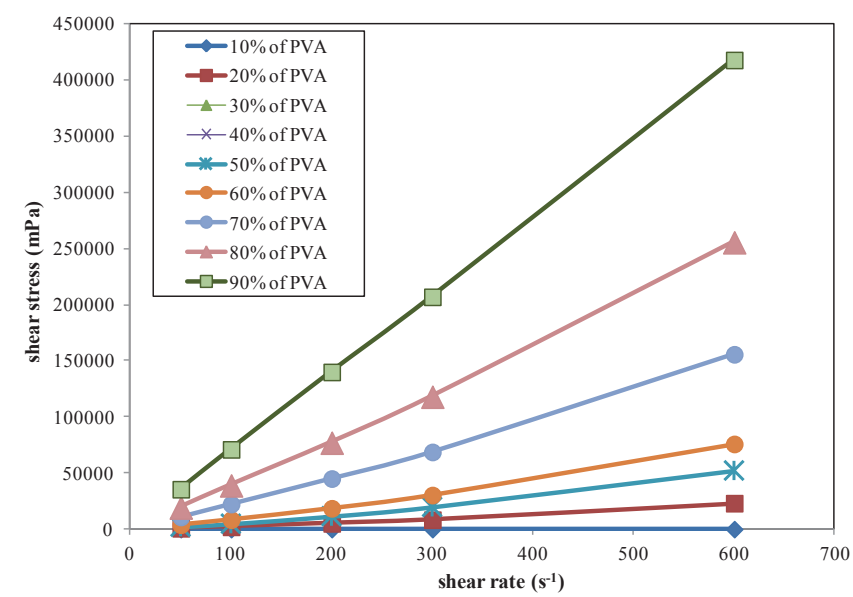

Fig. 6. Evolution of the shear stress with the percentage of PVA $\left(\mathrm{T}=25^{\circ} \mathrm{C}\right.$, apatite $: 4 \%)$

the shear stress $(\tau)$ according to the speed of shearing (D) was determined.

Fig.6 shows the effect of the addition of the \% of PVA on the rheological behavior of the suspension. Two modes can be described: The first type is: OSTWALD OF WAELE: $\tau=\mathrm{K}$ $\mathrm{D}^{\mathrm{n}}$ with $0<\mathrm{n}<1$ where $\mathrm{K}$ is an indication of consistency (in Pa. $\left.\mathrm{s}^{\mathrm{n}}\right), \mathrm{n}$ the index of flow (without dimension) and $\mathrm{D}$ speed of shearing. The second is of Bingham type: $\tau=\tau_{0}+\eta_{p} D$ where $\tau_{0}$ is the critical stress (Pa) and $\eta p$ the plastic viscosity (Pa.s) determined from the shape of the curves $\tau=f\left(D\left(s^{-1}\right)\right)$. Fig.6 shows that the behavior of dip solution (B.1, B.3, B.5, B.7, B.8, B.9, B.10, B.11) is of rheo-thickener type. The shear rate increases according to the speed of shearing D. According to the general law of behavior, these samples preserve a rheothickener behavior since the rheogram has concavities which are turned upwards. For the sample B.12, there is a passage behavior of rheo-thickener with a Bingham type behavior [29]. Therefore, it can be concluded that the sample B.12 presents a plastic behavior of Bingham type since the curve $\tau=\mathbf{f}\left(D\left(\mathbf{s}^{-1}\right)\right)$ is linear, $\boldsymbol{\eta}=\mathbf{f}\left(\mathbf{D}\left(\mathbf{s}^{-1}\right)\right)$ is decreasing. This interpretation is in accordance with the general law of behavior. The viscosity of this particular sample is about $7052 \mathrm{mPa}$.s. 
The reo-thickner behavior seems to be the best for a suspension prepared for such application. In fact, previous works [3, 26] mentioned such behavior as the best to cast a good microfiltration layer. A bingham behavior might be very viscous to facilitate the capillary suction phenomenon and thus the obtaining a homogenous layer. Suspension with a PVA percentage comprised between 10 and $80 \%$ can be apparently used to deposit the layer since they all have a rheo-thikner behavior.

\subsection{Microfiltration layer characterization}

Three layers were cast on clay tubular supports using three different suspension compositions (B.6, B.7 and B.8) and sintered at the same temperatures $\left(750^{\circ} \mathrm{C}\right)$. The casting time was fixed to $6 \mathrm{~min}$ which is the same time used in a previous work to prepare a microfiltration apatite membrane on apatite support [3]. Notice that clay supports, used in this study, have similar porous volume and average pore size than the apatite support used in the previous study [3]. Figure 7 shows the
SEM analysis of cross section and surface morphology of the obtained layers.

According to the SEM analysis, it can be noticed at first, that there is a good adhesion between the layer made of apatite and the clay support. No detachment is observed on the different cross section photographs. This result means that apatite powder is suitable to use as material to prepare a microfiltration layer on clay supports.

The optimal composition for coating suspension is obtained by using $40 \%$ PVA (B.7). This composition enables us to achieve a thickness of $45 \mu \mathrm{m}$ for microfiltration and homogeneous surface free from defects (such as cracks, etc.). On the other hand, the composition corresponding to $30 \%$ (B.8) PVA enables us to obtain a thickness of $10 \mu \mathrm{m}$, which is generally insufficient for the microfiltration layer [3] while the composition with 50\% (B.8) PVA led to a non-homogeneous surface. So, B.7 composition was retained for the preparation of a microfiltration membrane.
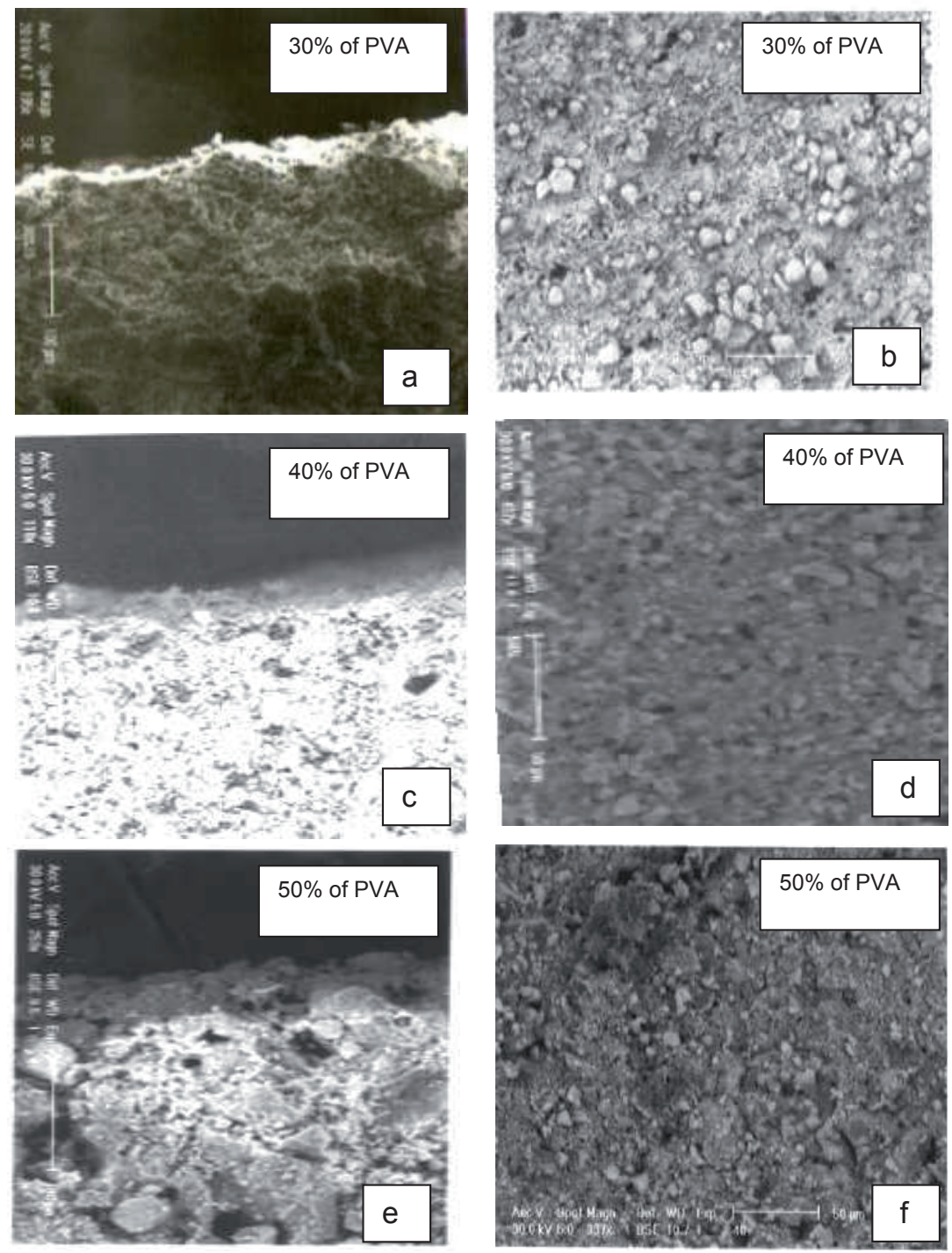

Fig. 7. SEM micrographs (cross section and surface) of active layer obtained with different slip compositions. (a) and (b) suspension B.6, (c) and (d) suspension B.7, (e) and (f) suspension B.8 
The average pore size of the optimized membrane was determined by mercury porosimetry and found to be $0.20 \mu \mathrm{m}$. This pore size value indicates that this kind of membrane can be utilized in the microfiltration range.

\section{Conclusion}

This paper shows very interesting results concerning the elaboration of an asymmetric composite microfiltration apatite/ clay membrane.

The viscosity and the rheological behavior of the suspension to be used to cast the apatite layer depends directly on the temperature, the stirring time, the powder and the binder (PVA) percentages. To obtain a suspension with a viscosity in the range of $25 \mathrm{mPa}$ s and having a rheo-thickner behavior at

\section{References}

1 Jana S., Purkait M. K., Mohanty K., Preparation and characterization of low-cost ceramic microfiltration membranes for the removal of chromate from aqueous solutions. Applied Clay Science, 47 (3-4), pp. 317-324, (2010).

DOI: 10.1016/j.clay.2009.11.036

2 Khemakhem S., Ben Amar R., Larbot A., Synthesis and characterization of a new inorganic ultrafiltration membrane composed entirely of Tunisian natural illite clay. Desalination, 206 (1-3), pp. 210-214, (2007).

DOI: $10.1016 /$ j.desal.2006.03.567

3 Masmoudi S., Larbot A., El Feki H., Ben Amar R., Elaboration and properties of new ceramic microfiltration membranes from natural and synthesised apatite. Desalination, 190 (1-3), pp. 89-103, (2006).

DOI: 10.1016/j.desal.2005.03.097

4 Mukasyan A. S., Costello C., Sherlock K. P., Lafarga D., Varma A., Perovskite membranes by aqueous combustion synthesis: synthesis and properties. Separation and Purification Technology, 25 (1-3), pp. 117-126, (2001).

DOI: $10.1016 / \mathrm{S} 1383-5866(01) 00096-\mathrm{X}$

$5 \quad$ Li Y., Zhang X., Wang J., Preparation for ZSM-5 membranes by a two-stage varying-temperature synthesis. Separation and Purification Technology, 25 (1-3), pp. 459-466, (2001). DOI: $10.1016 / \mathrm{S} 1383-5866(01) 00075-2$

6 Güler C., Balci E., Effect of some salts on the viscosity of slip casting. Applied Clay Science, 13 (3), pp. 213-218, (1998). DOI: 10.1016/S0169-1317(98)00018-0

7 Hanemann T., Viscosity change of unsaturated polyester-aluminacomposites using polyethylene glycol alkyl ether based dispersants, Composites: Part A: Applied Science and Manufacturing, 37 (11), pp. 2155-2163, (2006).

DOI: 10.1016/j.compositesa.2005.11.007

8 Zhang T., Evans J. R. G., Predicting the viscosity of ceramic injection moulding suspensions. Journal of the European Ceramic Society, 5 (3), pp. 165-172, (1989).

DOI: $\underline{10.1016 / 0955-2219(89) 90032-0}$ room temperature of 25 to $30^{\circ} \mathrm{C}$, the suspension should have a composition of $4 \%$ of apatite and $40 \%$ of PVA and stirred for 180 minutes.

The apatite layer is well attached to the clay support which proves that these materials can be used to prepare a composite microfiltration membrane. Temperature and PVA percentage are the most important parameters to control the active layer preparation.

The prepared layer had an average pore size diameter of 0.2 $\mu \mathrm{m}$ which is the range of a microfiltration membrane. The other conditions such as apatite powder size and origin, the sintering temperature, the casting time and information about the clay support were all taken from a previous work already published by our laboratory.
9 Tsetsekou A., Agrafiotis C., Milias A., Optimization of the rheological properties of alumina slurries for ceramic processing applications Part I: Slip-casting. Journal of the European Ceramic Society, 21 (3), pp. 363-373, (2001). DOI: 10.1016/S0955-2219(00)00185-0

10 Carpéna J., Donazzon B., Céraulo É., Prené S., Élaboration de ciments apatitiques composites pour la rétention du césium et de l'iode. Comptes Rendus de l'Académie des Sciences - Series IIC Chemistry, 4 (4), pp. 301-308, (2001). DOI: $10.1016 / \mathrm{S} 1387-1609(01) 01229-4$

11 Masmoudi S., Ben Amar R., Larbot A., El Feki H., Ben Salah A., Cot L., Elaboration of inorganic microfiltration membranes with hydroxyapatite applied to the treatment of wastewater from sea product industry. Journal of Membrane Science, 247 (1-2), pp. 1-9, (2005). DOI: $10.1016 /$ j.memsci.2004.03.047

12 Gbureck U., Barralet J. E., Spatz K., Grover L. M., Thull R., Ionic modification of calcium phosphate cement viscosity. Part I: hypodermic injection and strength improvement of apatite cement. Biomaterials, 25 (11), pp. 2187-2195, (2004). DOI: $10.1016 /$ j.biomaterials.2003.08.066

13 Gautier S., Champion E., Bernache-Assollant D., Chartier T., Rheological characteristics of alumina platelet-Hydroxyapatite composite suspensions. Journal of the European Ceramic Society, 19 (4), (1999), pp. 469-477. DOI: 10.1016/S0955-2219(98)00224-6

14 Montel G., Bonel G., Heugheubaert M., Trombe J. C., Rey C., New concepts in the composition, crystallization and growth of the mineral component of calcified tissues. Journal of Crystal Growth, 53 (1), (1981), pp. 74-99. DOI: $10.1016 / 0022-0248(81) 90057-9$

15 Azrour M., El Ammari L., Le Fur Y., Elouadi B., Etude Structurale D'Orthovanadates D'Alcalins et de Plomb Cristallisant avec la Structure Apatite Lacunaire. Journal of Solid State Chemistry, 141 (2), pp. 373-377, (1998). DOI: $\underline{10.1006 / \text { jssc. } 1998.7949}$ 
16 Liu D. M., Preparation and characterisation of porous hydroxyapatite bioceramic via a slip-casting route. Ceramics International, 24 (6), pp. 441-446, (1998).

DOI: $10.1016 / \mathrm{S} 0272-8842(97) 00033-3$

17 Zhang Y., Yokogawa Y., Feng X., Tao Y., Li Y., Preparation and properties of bimodal porous apatite ceramics through slip casting using different hydroxyapatite powders. Ceramics International, 36 (1), pp. 107-113, (2010).

DOI: $\underline{10.1016 / \text { j.ceramint.2009.07.008 }}$

18 Chaari K., Bouaziz J., Bouzouita K., Rheological behavior of organic suspensions of fluorapatite. Journal of Colloid and Interface Science, 285 (2), pp. 469-475, (2005). DOI: $10.1016 /$ j.jcis.2004.12.026

19 Liu D. M., Preparation and characterisation of porous hydroxyapatite bioceramic via a slip-casting route. Ceramics International, 24 (6), pp. 441-446, (1998).

DOI: $10.1016 / \mathrm{S} 0272-8842(97) 00033-3$

20 Gautier S., Champion E., Bernache-Assollant D., Chartier T., Rheological characteristics of alumina platelet-Hydroxyapatite composite suspensions, Journal of the European Ceramic Society, 19 (4), pp. 469-477, (1999). DOI: $10.1016 / \mathrm{S} 0955-2219(98) 00224-6$

21 Fischer P., Pollard M., Erni P., Marti I., Padar S., Rheological approaches to food systems. Comptes Rendus Physique, 10 (8), pp. 740-750, (2009).

DOI: $10.1016 /$ j.crhy.2009.10.016

22 Dufauda O., Marchal P., Corbel S., Rheological properties of PZT suspensions for stereolithography. Journal of the European Ceramic Society, 22 (13), pp. 2081-2092, (2002). DOI: $10.1016 / \mathrm{S} 0955-2219(02) 00036-5$
23 Nguyen C. T., Desgranges F., Roy G., Galanis N., Mare T., Boucher S., Angue Mintsa H., Temperature and particle-size dependent viscosity data for water-based nanofluids - Hysteresis phenomenon. International Journal of Heat and Fluid Flow, 28 (6), pp. 1492-1506, (2007).

DOI: $10.1016 /$ j.jijheatfluidflow.2007.02.004

24 German R. G., Powder Injection Molding. Metal Powder Industries Federation, Princeton, (1990).

25 Hanemann T., Influence of particle properties on the viscosity of polymer-alumina composites. Ceramics International, 34 (8), pp. 2099-2105, (2008).

DOI: $10.1016 /$ j.ceramint.2007.08.007

26 Jedidi I., Saïdi S., Khmakem S., Larbot A., Ammar N. E., Fourati A., Charfi A., Ben Amar R., New ceramic microfiltration membranes from mineral coal fly ash. Arabian Journal of Chemistry, 2 (1), pp. 31-39, (2009). DOI: $10.1016 / j$.arabjc.2009.07.006

27 M'bodj O., Ariguib N. K., Ayadi M. T., Magnin A., Plastic and elastic properties of the systems interstratified clay-water-electrolytexanthan. Journal of Colloid and Interface Science, 273 (2), pp. 675-684, (2004). DOI: $10.1016 /$ j.jcis.2004.02.028

28 Coussot P., Grossiord J. L., Comprendre la Rhéologie: De la circulation du sang à la prise du béton. Édition Diffusion Presse Sciences, (2001).

29 Wallevik J. E., Relationship between the Bingham parameters and slump. Cement and Concrete Research, 36 (7), pp. 1214-1221, (2006). DOI: $10.1016 /$ j.cemconres.2006.03.001 